\title{
Survival rate, adaptation ability and carbon production and sequestration of 21 green oak (Quercusrotundifolia Lam.) provenances at Mounts of Saida (western Algeria)
}

Hadj Khatir ( $\square$ khatir_hj67@hotmail.ca )

ReprodBiotech and stem cell https://orcid.org/0000-0002-4595-6204

Nasrallah Yahia

Universite Dr Tahar Moulay de Saida

\section{Research}

Keywords: Carbon, development, origin, planting, sequestration, Quercus rotundifolia, survival, total height, semi-arid, Algeria

Posted Date: October 12th, 2021

DOI: https://doi.org/10.21203/rs.3.rs-934157/v1

License: (c) (i) This work is licensed under a Creative Commons Attribution 4.0 International License. Read Full License 


\section{Abstract}

Due to recent global changes, a substantial degradation of natural ecosystems in North Africa and difficulties of species regeneration have been observed. A comparison of 21 green oak (Quercus rotundifolia Lam.) provenances in different bioclimatic zones was carried out at two ecologically different stations in western Algeria. The main objectives of the study were to (a) assess the survival rate and development in the natural environment of young individuals who derive from it, (b) gain an understanding of the level of morphological variability and (c) explore the possibilities of adapting the different provenances of green oak in the west Algerian ecological regions. The field trial was established in 2008 at two sites. The average survival rate ten years after the establishment of the field trial was $38.50 \%$, with a total height average of $122.95 \mathrm{~cm}$, a dry epigeous biomass production of $0.0630 \mathrm{t} / \mathrm{ha}$ and a sequestered amount of atmospheric carbon $\left(\mathrm{CO}_{2}\right)$ of $0.0859 \mathrm{t} /$ ha. The green oak provenance (origin) of Zaccar from the Tellian Atlas group is distinguished by a higher survival rate and dryer epigeous than other origins. The variability of large regions of the country means that there are four areas in which varieties can show superiority in survival and biomass: those representing the Northern part of the Saharan Atlas, those of the high inner plains, those of the southern facade of the Tellian Atlas and finally those of the Saharan Atlas.

\section{Introduction}

Forests in the Mediterranean region play an essential role in maintaining natural resources. They protect water supplies and soil (Harris et al., 2006; Choi et al., 2008; Vennetier and Ripert, 2010; Woodworth, 2013) and regulate the local climate by increasing air humidity and decreasing the intensity of droughts (Kelly and Goulden, 2008; Jump et al., 2009; Matas and Jump, 2014). In addition, they constitute a barrier against desertification and soil erosion (Boulmane et al., 2013; Nasrallah and Khelifi, 2010). With their extraordinary biomass production capacity, these forests are also very important for forage production and atmospheric carbon sequestration (Castro et al., 2004; Sebei et al., 2004; Tsoumou et al., 2016).

However, in the southern and eastern Mediterranean areas, woodland rates are very low, especially those of deciduous woodland. In fact, they represent are less than $10 \%$ in the countries located at the South Shore. According to the food and agriculture organization (FAO; 2010 ) and Lanly (2010), the average rate of deforestation ranges from 0.72 to $1.1 \%$.

In this region, tree growth is limited by the amount of water available in the soil. A decrease in the amount of available water causes a decrease in carbon assimilation, which is an essential component for the primary growth and for tree reserves of this important element. Many researchers (Quezel and Medail, 2003; Somot et al., 2008; Limousin, 2009) have confirmed that due to climate change, a significant decrease in precipitation and an increase in the duration and intensity of summer droughts will occur. Oaks once made up a major part of these forests and are considered to be one of the most typical components of Mediterranean vegetation-type (Saleo and Lo Gullo, 1990; Tsakaldimi et al., 2005). However, these ecosystems have deteriorated and are currently experiencing difficulties in their regeneration (Dey et al., 2008; MacDougall et al., 2010; Pandey et al., 2020). This is particularly the case for green oak, which needs to be reconsidered in the various political regulations of plant restoration (Castro et al., 2006; Dey et al., 2008; Leverkus et al., 2015). This species requires a minimum rainfall of $355 \mathrm{~mm} /$ year to balance the annual carbon cost related to photosynthesis (Gracia, 2006).

To resolve this issue, research has been done on green oak regeneration procedures by planting, and these studies are providing promising preliminary results. Some of these procedures include a) plantation trials of nurse plants (Padilla and Pugnaire, 2009; Bergoin, 2011; Farlee, 2013), b) using physical means (plastic boxes, mesh, etc.), c) adding chemicals to protect the acorns from predators (Gomez and Hedar, 2008; Castro et al., 2015), and d) the employment of large pouches for growing plants, which allow a good root burial (Dominguez-Lerena et al., 2006; Chirino et al., 2008; Tsakaldimi et al., 2009). Until now, progress has been made in avoiding high mortality in the first two years after planting (Nardini et al., 2000; Tsakaldimi, 2001; Villar-Salvador et al., 2004).

The objective of the current study is to explore an alternative approach to ensure the restoration of the green oak forest by improving its survival and productivity. The comparison of green oak provenances (origins) at different bioclimatic zones was carried out in two ecologically different stations. Evaluation of the behaviour of these origins can provide answers to important questions: what is the influence of ecological conditions on reforestation failure and what possible ecotypes could be appropriate to adopt in future reforestation programmes?

\section{Materials And Methods}

\subsection{Plant materials}

Based on a survey of the territorially competent forestry services and the literature about the distribution of green oak in northern Algeria, important information on the different stands of the species was collected. Sampling was carried out by geographical area to establish the distribution of genotypes according to bioclimatic ranges. The fruit harvest (glands) was done on the entire crown, with respect for the minimum distance $(300 \mathrm{~m})$ between the seeders. This distance is necessary to avoid harvesting from trees that potentially have the same parents (Figure1 
and Table 1). The green oaks that are geographically very close and ecologically identical were removed from sampling. The 21 selected green oak origins were collected over the following four bioclimatic zones:

a. Group I: represents the most climatically advantageous region for oak growth and corresponds to the sub-humid floor of the Tellian Atlas. The selected origins were: Oued Yesser (OTM), Zaccar (ZAM) and Chaâbat Lakhra (CLS).

b. Group Il: corresponds to the sub-humid floor with the fresh and cold variants of thesouthern Tellian region. The selected origins were from Théniet El-Had (THT), Bordj-Bounaâma (BBT), Frenda (FRT), Cascade (CSG), El Bordj (BDM), Guelma (GLM), Nador (ZBA) and Sebt (SBR).

c. Group III: represent the semi-arid zone of the plains and mountains that contains large areas of green oak in the state of clear and degraded thickets. The sampling was done on Ouled Kada (OKS), Oum Djerane (DLS), Nesmoth (MSN), Mezaouro (MSB) and Sebdou (SET).

d. Group IV: represents the zone of the Saharan Atlas. In this zone, the green oak is less abundant and grows in extreme climatic conditions. The selected origins were Belezma (BLD), Dar Echioukh (DED), Boualem (BAM), Sidi Bouzid (ZBA) and Jebel Aissa (ATS).

\subsection{Device and experimental plan}

After a year of nursery breeding in sachets $(30 \times 9 \mathrm{~cm})$, the plants were set up in pots $(50 \times 50 \times 50 \mathrm{~cm})$, with a gap between the plants of $3 \times 3 \mathrm{~m}$. Each of the devices was installed in a previously prepared field during the winter of 2006 to 2007 . Two sites at Saida forest were selected for planting. The first site (1), known as 'Sidi Benkadour', has an average altitude of $1260 \mathrm{~m}$, a longitude of 34-45' $005 \mathrm{~N}$ and a latitude of 026 ' 423 $\mathrm{E}$, with an N-N-O exposure and an average slope of 5 to $10 \%$. This site is characterised by: a) the high plant dynamic stage of shrubs dominated by Quercus rotundifolia, Juniperus oxycedrus and Ampelodesmamauritanicum, b) medium dynamic potentialities in fresh semi-arid bioclimates with rainfall greater than $500 \mathrm{~mm}$ on brown fersiallitic soil with limono-argilo-sandy, 21 to $60 \mathrm{~cm}$ deep, at 0-10/ 1000 active limestone and c) good biological activity at Jasminum fruticans, Smilaxasperaand Clematis flammula. The second site (2), known as 'Sidi Moussa', has an average altitude of $1235 \mathrm{~m}$, a longitude of 34-41' $5443 \mathrm{~N}$ and a latitude of 018 ' $3915 \mathrm{E}$, with a western exposure and an average slope of 3 to 7\%. It is characterised by: a) the clear high matorral phytodynamic stage dominated by Juniperus oxycedrus, Pistacia lentiscus and Stipa tenacissima, with b) mediocre dynamic potentialities in semi-arid cold lower bioclimates, rain-fedness between 350 and $400 \mathrm{~mm}$ on modal limestone brown soil, with a limono-sandy texture, 11 to $30 \mathrm{~cm}$ deep, active limestone at 0-10/ 1000 and c) an average biological activity at Alluim paniculatum, Euphorbia falcata, Malva rotundifolia and Avena sterilis.

The two comparative plantations are installed according to a plot scheme to facilitate management. Each device consists of three plots installed horizontally and side by side on relatively flat ground on the lower part of the slope. Each plot contains the 21 provenances randomly distributed perpendicular to the slope and contains 15 families of the same provenance, based on 10 plants per family, for 9450 plants per site. The monitoring of survival ability and total heights was conducted regularly and without any restocking of plants.

The survival rate by origin (the ratio of the number of live shrubs to the initial number of individuals planted) was estimated by a systematic count of the number of samples alive by family, origin and plot. For each shrub, the measurements taken were the total height and the root collar diameter.

A 3-metre measuring tape was used to obtain measurements (height and a sliding foot diameter). To prevent plant destruction, only one shrub per plot and per origin was felled in each plantation for the measurements of epigeous biomass and carbon sequestration. The determination of the aerial biomass of shrubs from the 21 green oak origins was based on the monitoring of individuals-diameter at the medium collar. Once the shrub with the median collar diameter in each plot had been determined, it was felled. The trunk (main shafts), branches and leaves were separated and weighed on the spot by the use of a precision scale. Samples of each part were placed in well-sealed numbered bags. For the trunk, after measuring the length, three pieces of $10 \mathrm{~cm}$, (bottom, middle and the top of the crown) were taken. For branches and leaves, a $100 \mathrm{~g}$ sample of each was taken. The operation was repeated for the average shrub of each of the 21 provenances and in the three plots of each plantation. Every week, 20 subjects from each provenance were cut and transported to the laboratory. Depending on the laboratory's drying capabilities, 189 samples per planting were determined. The different parts were repainted and dried at $65^{\circ} \mathrm{C}$ for 24 hours to determine their dry weights. The dry weights of the different parts were calculated according to the fresh weight measured on the ground. The sum of the different dry parts (trunk, branches and leaf) represents the dry aerial biomass of the shrub from each origin.

Provenance biomass measurements were taken at the end of the nursery reproduction period (10 months later). The averages of the dry aerial biomass of the 63 shrubs felled in each of the two plantations were modelled on the basis of diameter and/or height. The best correlation is used to calculate the rest of the shrubs in the plantation. The allometric regression models selected in our case are mentioned with their characteristics in Table 2. The total dry biomass of the plantation is obtained by multiplying the number of shrubs of the plantation with the data from the average tree. The total dry biomass per hectare is then deducted.

The carbon stock of each plantation is obtained by determining the amount of carbon (C) of each shrub, which is only the product of the air biomass dry by $0.47 \%$. The atmospheric carbon stock (CO2) of a shrub is obtained by multiplying the amount of $\mathrm{C}$ calculated by 3.67 . In the same

Page $3 / 14$ 
way as for dry biomass, the carbon stock per hectare or planting will be calculated.

Considering that, the value of an $\mathbf{X}$ character of an individual $\mathbf{k}$ of origin i in a medium $\mathbf{j}$ is written in the form of $\overrightarrow{\mathbf{X i j}} \mathbf{k}=\mathbf{u}+\mathbf{P i}+\mathbf{M j}+(\mathrm{PM}) \mathbf{i j}+\mathbf{R i j k}$ Where $\mathbf{u}=$ general average, $\mathbf{P i}=$ effect of origin $\mathbf{i}, \mathbf{M j}=$ effect of the medium $\mathbf{j}$ (station effect), $(\mathbf{P M}) \mathbf{i j}=$ interaction origin $\mathbf{x}$ medium, and $\mathbf{R i j k}=$ residual error.

\subsection{Statistical treatment}

Survival rate data are converted to arc sin before analysis. We tested the origin effect ${ }^{x}$ site (station) on our measurements by a 2 -factor variance analysis (ANOVA) at the $5 \%$ risk threshold (Stastistica 12). This analysis was supplemented by a multiple comparison of the averages by the Newman-Keuls test. It should also be noted that the study of interfamily variability will not be addressed in this article.

\section{Results}

The preliminary evaluation of the juvenile period (nursery stage and one year after planting) is now possible, permitting the study of the behaviour of different origins 10 years after the seedling (Nasrallah and Khélifi, 2010).

\subsection{Effect of the station}

Survival and plant height measurements taken one month after planting (winter 2007) did not reveal significant differences between the two sites. However, the measurements taken nine years later were significant. The Newman-Keuls tests show that the green oak origins reacted differently to the environmental conditions.

Plant survival was higher at the Sidi Benkadour site (46\%) compared to the Sidi Moussa (31\%) plantation site. The pedoclimatic conditions of the first site seem to be more suitable for these 21 green oak origins than those of the second site (Table 3 ). We noted also that many plants rated dead (either due to a lack of water or grazing by wildlife) were able to resume again as a result of improved weather conditions. The plant height growth at the first site was $132.10 \mathrm{~cm}$ compared to the second site, which was $113.80 \mathrm{~cm}$.

The differences in survival and total heights recorded in the two plantations, 10 years after planting, explain the significant differences in biomass production and carbon sequestration between the two sites (Table 4). The 21 green oak provenances were better expressed at the first site, producing $417.87 \mathrm{~g}$ of total fresh biomass (TFB) and $159.26 \mathrm{~g}$ of carbon, compared to the second site, which produced $402.04 \mathrm{~g}$ of TFB and $144.09 \mathrm{~g}$ of carbon.

The average amount of atmospheric carbon sequestered at the first site was $0.2987 \mathrm{t} \mathrm{CO2} / \mathrm{ha}$ compared to $0.1820 \mathrm{t}$ of $\mathrm{CO} 2 / \mathrm{ha}$ at the second site. The amount of $\mathrm{CO} 2$ sequestered in the first plantation was $2.54 \mathrm{t}$ of $\mathrm{CO} 2$, compared to $1.55 \mathrm{t}$ of $\mathrm{CO} 2$ in the second one.

The average production of fresh biomass was $0.2136 \mathrm{t} /$ ha at the Sidi Benkadour site, compared to only $0.1385 \mathrm{t} / \mathrm{ha}$ at the Sidi Moussa site. A total fresh biomass production of $1.82 \mathrm{t} /$ ha was obtained at the first site, compared to $1.18 \mathrm{t} / \mathrm{ha}$ at the second site.

\subsection{Inter-provenance variability}

\subsubsection{Evolution of plant survival and total height plants}

The variance analysis of survival criteria, which was done one month after planting, had no significant effect on either the sites or provenances. Both sites recorded very low mortality (0.01\%). This result shows that transplant shock was prevented (Nasrallah, 2014).

Measurements taken at the end of autumn 2016 in both sites recorded the survival of $38.5 \%$ of the plants. Survival varied significantly (at the threshold of $\mathbf{a}=0.05 \%$ ) between sites and within the sites themselves, but without interaction between site and origin. Based on analysis of the Newman-Keuls tests, origins were divided into six homogeneous groups (HG) in the first site and seven HG in the second one (see Table $\mathbf{3}$ ):

1. At the site of Sidi Benkadour (1), the origin of Boualem, belonging to the ecological group of the Saharan Atlas, had the highest survival rate (57\%), whereas the provenance of Sour Ghozlane of the fourth ecological group had the lowest survival rate (29\%).

2. At the Sidi Moussa site (2), the dar Echioukh origin survival rate was $40 \%$ in comparison to $20 \%$ for of Oued Yesser origin.

3. The provenances of Saharan Atlas group responded better to the conditions of the plantations of the sites. However, provenances of the northern side of the Tellian Atlas, and to a lesser extent those of its southern side, were responded poorly to the conditions of the sites.

The variance analysis done on the total heights of the plants, one month after planting, revealed a significant effect on the provenance ( $\mathrm{a}=$ $0.05 \%)$, but not on the sites. The average total height (ATH) for the entire plantation was $17.28 \mathrm{~cm}$. 
Height measurements taken in both plantation sites at the end of autumn 2016 recorded an ATH of $122.95 \mathrm{~cm}$. The ATH of the plants varies significantly ( $a=0.05 \%$ ), between the provenances at each site and between the sites, with the presence of an interaction origins $x$ sites. Analysis of the Newman-Keuls tests put the g provenances of the first site into eight groups, compared to six groups in the second one:

1. The Boualem and Jebel Aissa origins from the ecological group of the Saharan Atlas are distinguished by a larger ATH of $157.65 \mathrm{~cm}$ and $139.26 \mathrm{~cm}$ in the first and second site, respectively. The best second origin is reserved to Zaccar $(139.30 \mathrm{~cm})$.

2. The ATH of origins of Guelma were $121.27 \mathrm{~cm}$ in the first site and $98.36,99.64$ and $102.58 \mathrm{~cm}$ for Bordj Bounaama, Oued Yesser and Belezma provenances, respectively, at the second plantation site.

3. The green oak origins of the Saharan Atlas ecological group recorded the highest ATH in both sites, while those of the Tellian Atlas showed the lowest ATH at the both sites.

\subsubsection{Fresh biomass and carbon sequestration from origins}

The average total fresh biomass (TFB) ranged from $1.15 \mathrm{~g}$ to $5.19 \mathrm{~g}$. The analysis formed 11 homogeneous groups. The highest weights were recorded for the provenances of Zaouet, Bel Abed and Dar Echioukh and the lowest weight was recorded by the provenance of Câbet Lakhra (Nasrallah, 2014). Analysis of the variance (at the threshold of $\mathbf{a}=0.05 \%$ ), TFB of the aerial parts of the plants of the two sites (from seedling until 10 years of age) revealed $1.15 \mathrm{~g}$ to $5.19 \mathrm{~g}$.

The analysis formed 11 homogeneous groups. The highest weights were recorded by the provenances of Zaouet, Bel Abed and Dar Echioukh and the lowest weight by Câbet Lakhra (Nasrallah, 2014). Analysis of the variance (at the threshold of $\mathbf{a}=0.05 \%$ ), TFB of the aerial parts of the plants of the two plantation sites (from seedling until 10 years of age) revealed significant differences between the provenances of each site and also between the two sites, with a remarkable interaction between site and provenance.

The Newman-Keuls tests divided the provenances at the first site into nine groups and those at the second site into two groups (Table4). The Zaccar and Jebel Aissa origins from the northern ecological region the Tellian Atlas and the Saharan Atlas groups were characterised by TFB. The TFB production at the first site and second site was 474.22 and $461.79 \mathrm{~g}$, respectively. The TFB production of the provenances from Oued Yesser, Chaâbet Lakhra, Bordj Bounaama, El Bordj, Frenda, Gulema, Sebdou and Mezaouro was low at the first site.

The ecological group of the Saharan Atlas produced the highest TFB average at both sites. The average biomass production of provenance of the northern part of the Tellian Atlas was higher than those of the second site. Nevertheless, the provenances of the second and third ecological groups produced the lowest TFB.

The calculation of TFB in t/ha at Sidi Benkadour showed that the provenances of the Saharan Atlas, followed by those of the inner plains, have the highest production with 0.0110 and $0.0092 \mathrm{t} / \mathrm{ha}$, respectively. The origins of the two slopes of the Tellian Atlas (south and north) have a low TFB/ha value (south: 0.0099 t/ha, north: 0.0079 t/ha). Concerning the Sidi Moussa site, the origin TFB/ha values were not important. The provenances of the Saharan Atlas $(0.0068 \mathrm{t} / \mathrm{ha})$ and those of the inner plains $(0.0067 \mathrm{t} / \mathrm{ha})$ have better TFB/ha production than the southern ( $0.0060 \mathrm{t} / \mathrm{ha})$ and the northern $(0.0053 \mathrm{t} / \mathrm{ha})$ slopes of the Tellian Atlas.

In the first site, the provenance of the Saharan Atlas and the south of Tellian Atlas sequestered amounts of CO2 above the general average (0.0154 t CO2/ha and 0.0138 t CO2/ha, respectively). Concerning the two others provenances of the southern intern plains of Tellian Atlas ecological zones and the northern part, the quantity of $\mathrm{CO}_{2}$ sequestered was $0.0129 \mathrm{t} \mathrm{CO} 2 /$ ha and $0.0111 \mathrm{t} \mathrm{CO} 2 /$ ha respectively. A lesser amount of $\mathrm{CO} 2$ was sequestered at the second site, with higher averages for the Saharan Atlas (0.0090 t CO2/ha) and inner plains (0.0089 t CO2/ha) when compared to those in the southern (0.0078 t CO2/ha) and northern Atlas (0.0071 t CO2/ha) groups.

\section{Discussion}

\subsection{Effect of the medium}

An average survival of $38.50 \%$, nine years after planting, was recorded in both sites, compared to $49 \%$ for the first three years from planting. This result seems to be related to the warmth and drought phenomena during the firsts two summers, which induced a high rate of mortality of green oak plants in the Mediterranean region (Peman et al., 2006; Nasrallah, 2014; Prévosto et al., 2015). The temperature and amount of water are critical to the survival and growth of plants of this species during the first two years (McCreary, 2009; Tsakaldimi et al., 2009; Gonza et al., 2011). Improving the physiological status of green oak seedlings under shrub cover, in addition to root burial, can potentially reduce perspiration and water stress of seedlings without affecting photosynthesis (Pausas et al., 2009; Prévosto et al., 2013). This is the case of our two open forest plantations, which contain shrubby vegetation that provides shelter and/or nurse for the oak species. In addition, it will permit the colonisation of the deep layers of soil by the roots, which increases the opportunity of producing the best seedlings (Gömez-Aparicio etal., 2004; Manrique and Reque, 2014). However, as reported in our results, the plant survival was different according to the site location and was $46 \%$ in the Sidi 
Benkadour site compared to $31 \%$ in the Sidi Moussa site. This difference of $15 \%$ in green oak survival observed between the two sites is mainly due to local environmental conditions, which are represented by the pedoclimatic characteristics of each site.

The effect of the environment on planting is also distinguished, through the evolution of the height growth and the aerial biomass of the plants. Indeed, the average total height and the TFB at the Sidi Benkadour site were significantly higher than those at the Sidi Moussa site. These indicators of plant growth are influenced by the interaction between the origin (provenance) and the environment. Nevertheless, the differences in growth between planting environments seem to be more important than the differences between origins (Sotelo Montes et al., 2003; Rochon et al., 2007; Weber and Sotelo Montes, 2005). The origin interaction ${ }^{\mathbf{x}}$ site is a constant concern for the breeder. If the variability between provenances and/or their order of classification is not preserved at the different environments tested, origin ${ }^{\mathbf{x}}$ environment interaction will be considered as reference (Kremer, 1986a; Vernier and Teissier Du Cros, 1996). The annual average growth in each studied site was around $15 \mathrm{~cm} / \mathrm{year}$, which was slightly higher than those reported by the Zitouni study (2010) regarding the Setif region (west of Algeria).

\subsection{Behaviour of origin}

Studies on the reproduction of green oak species have been more focused on the survival difficulties encountered by this species during the early years of its regeneration (Tsakaldimi et al., 2005; Smit et al., 2009). However, there is some data on the behaviour and the adaptation of the green oak provenances of this species after the juvenile period. In our current study, the origins from various bioclimatic zones and the choice of two ecologically different plantation sites made it easier to detect the behaviour of green oak species according to its provenance. The change in the order of provenances from one site to another indicates the importance of the effect of the medium and/or the environment of origin (Kremer, 1986a; Vernier and Teissier Du Cros, 1996).

Due to the climatic and edaphic differences between the two sites, the green oak survival of the four group provenances was more successful at the first site than at the second. Although both sites have the same south-north direction, it appears that the first site is more favourable to the survival of the species.

In addition, it was found that the height growth of the plants is highly dependent on the expression of the original origins based on the local environmental conditions (annual variation in temperature and severity of drought) at each site.

If the growth of the seedlings of the four provenances groups showed an advantage for the first site, those of the Saharan Atlas group responded effectively to the environmental conditions in both sites. For the three remaining groups, the two sites of planting were more favourable to their growth due to: a) the distance that separated them from each group, b) the degree of similarity between sites, 3) the climatic conditions and 4) the soil characteristics of each origin.

Growing the biomass of green oak by selecting the most suitable provenance for reforestation will contribute to an increase of organic substrate in the soil, as well as to the sequestration of more carbon (Oubrahim et al., 2015; Horak et al., 2019). Of the provenances from semi-arid forest ecosystems, those in the northern Zaccar (Tellian Atlas) showed the best results in the production of epigeous biomass at the first site and those in the Jebel Aisssa (Saharan Atlas) showed the best results in the production of epigeous biomass at the second site. For the Saharan Atlas group, this could be due to the climatic conditions (soil moisture), that were offered by the two sites, allow the highest averages of epigeous biomass and the highest amounts of sequestered carbon. The other four ecological groups (Oued Yesser, Chaâbet Lekhra, Bordj and Frenda) manifested average amounts of biomass and lower sequestration carbon levels at the both sites. This can be explained by less favourable climatic conditions at the introductory sites compared to the source sites (Pugnaire et al., 2001; Smit et al., 2009). Differences in provenances behaviour at both sites were studied by Pugnaire et al. (2009), Leverkus et al. (2015) and Horak et al. (2019). These authors found that the humidity and the altitude improve the survival and biomass production of green oak by improving the level of nitrogen in the leaves and by the reduction of drought stress.

In semi-arid forest ecosystems, such as the present one, the management measures taken to promote green oak biomass should thus contribute (directly via tree biomass and indirectly through the increase in soil organic material) to improve carbon sequestration (Oubrahim et al., 2015).

The average annual fresh epigeous biomass obtained at the Sidi Benkaddour and Sidi Moussa sites was very low compared to those reported by Zitouni (2010) in the forests of Setif in the north-east of Algeria (1:10; with an average of $0.03 \mathrm{t} / \mathrm{ha} / \mathrm{year}$ vs. $0.3 \mathrm{t} / \mathrm{ha} / \mathrm{year}$ respectively). The low amount obtained in our study may be related to the young age of the plantations.

The same observation can be concluded concerning the amount of carbon sequestered, which was very low at the Sidi Benkaddour and Sidi Moussa sites in comparison with those found at Puschabon (Montpellier, France) by Lempereur et al. (2018) using older stands. According to Gratini et al.(2011), Quercus ilex can play an important role in reducing carbon dioxide concentration and in decreasing the air and soil temperature in the Mediterranean basin regions.

\section{Conclusion}


This study contributes to the understanding of the constraints of the recovery of the green oak species in the Mediterranean region, which has experienced a significant regression, especially in the southern part of the Mediterranean. The study compared the behaviour of 21 selected provenances in the main ecological regions of green oak of the west of Algeria (Mounts of Saida). The follow-up spanned nine years and analysed adaptation to the environment such as survival, growth, epigeous biomass and carbon sequestration of shrubs. Measurements taken between January 2008 and October 2016 revealed:

- Variability in the area of green oak in Algeria concerning the two criteria studied: the survival and the height growth averages in the two different sites. The favourable pedoclimatic conditions at the first site induce a significant difference regarding the survival rate (46\% vs. $31 \%$ ) and growth in average total heights $(132 \mathrm{~cm}$ vs. $114 \mathrm{~cm}$ ) of the two plantations at the Sidi Benkadour and the Sidi Moussa sites respectively.

- Variability within the large regions, characterized by a relatively stable classification from one region to another. In addition to superiority in survival and vigour of the provenance of the groups of the Tellian Atlas north and south, which reacted better to the more favourable conditions of the first site? However, the provenance of the groups of the Saharan Atlas and, to a lesser extent, those of the internal plains, was highly expressed on the second site.

- Production of epigeous biomass and varying amounts of sequestered $\mathrm{CO}_{2}$, depending on the zone from which the green oak provenance was taken. With the exception of the Zaccar origin, belonging to the group of the northern Tellian Atlas, the rest of the origins were classified according to a south-north cline. The provenances of the Saharan Atlas have an important biomass and $\mathrm{CO} 2$ sequestration compared to the others groups.

In conclusion, the selection of a suitable provenance from the southern region of green oak specie for reforestation in the north region, can contribute to the choice of climate-resistant provenance for better survival, and can improve biomass production as well as carbon sequestration. This approach, compared to other techniques employed for plant regeneration, can be adapted to current trends and to overcome the future risk of an increase in temperature and aridity in the Mediterranean region.

These results should be reinforced by surveys of new genetic provenances at each ecological region by further sampling of the green oak in the southern geographic area and in the southern part of the Tellian Atlas in the case of Zaccar provenance.

\section{Abbreviations}

ATH: Average of total height ATH

ATS : Jebel Aissa

BBT: Bordj-Bounaâma

BDM: El Bordj

BLD: Belezma

Boualem: BAM

C: Carbon

CLS: Chaâbat Lakhra

CSG: Cascade

DED: Dar Echioukh

DLS: Oum Djerane

DTB: dry total biomass

E: East

FAO: Food and Agriculture Organization.

FRT: Frenda

GLM: Guelma

ha: Hectare. 
m: Meter

MSB: Mezaouro

MSN: Nesmoth

$\mathrm{N}$ : North

0 : Ouest

OKS: Ouled Kada

OTM: Oued Yesser

SBR: Sebt

SET: Sebdou.

Sidi Bouzid: ZBA

t: tonnes

TFB: total fresh biomass

THT: Théniet El-Had

ZAM: Zaccar

ZBA: Nador

\section{Declarations}

1. Ethics approval and consent to participate: Not applicable.

2. Consent for publication: Not applicable.

3. Availability of data and material: Not applicable.

4. Competing interest: Not applicable.

5. Funding: Not applicable.

6. Author's contributions:

- Nasrallah Yahia: Conception of the study, analysis and interpretation of obtained data, writing of the draft French paper-version.

- Hadj Khatir: Substantive revising of the work, translation to English, deep reviewing and editing.

Acknowledgments: The authors thank the foresters for the conservation of the forests of Saida and the district of Hassasna.

\section{References}

1. Castro J, Leverkus AB, Fuster F (2015) A new device to foster oak forest restoration via 418 seed sowing. New Forests (accepted with pending revision)

2. Castro J, Zamora R, Hódar JA (2006) Restoring Quercus pyrenaica forests using pioneer shrubs as nurse plants. Appl Veg Sci 9:137-142

3. Castro J, R Zamora R, Hódar JA, Gómez JM, Gómez-Aparicio L (2004) Benefits of using shrubs as nurse plants for reforestation in Mediterranean mountains: a 4-year study. Restor Ecol 12:352-358

4. Chirino E, Vilagrosa A, Hernandez El, Matos A, Vallejo VR (2008) Effects of deep container on morpho-functional characteristics and root colonization in Quercus suber L. seedling for reforestation in Mediterranean climate. For Ecol Manage 256:779-785

5. Choi YD, Temperton VM, Allen EB, Grootjans AP, Halassy M, Hobbs RJ, Naeth MA, Torok K (2008) Ecological restoration for future sustainability in a changing environment. Ecoscience 15:53-64

6. Dey DC, Jacobs D, McNabb K, Miller G, Baldwin V, Foster G (2008) Artificial regeneration of major oak (Quercus) species in the eastern United States a review of the literature. Forest Science 54:77-106

7. Dominguez-Lerena S, Herrero N, Carrasco I, Ocana L, Penuelas JL, Mexal JG (2006) Container characteristics influence Pinus pinea seedlings development in the nursery and field. For EcolManage 221:63-71 
8. FAO (2010) Assessment of Global Forest Reorigins, Rome: 92-95

9. Farlee LD (2013) Direct seeding of fine hardwood tree species. In Proceedings of the Seventh Walnut Council Research Symposium GTR-NRSP-115: 31-47

10. García Martínez MS (2006) Antracoanalysis of Phase Il of Punta de los Gavilanes (Puerto de Mazarrón, Murcia). Thesis of Unpublished Bachelor's degree. University of Murcia

11. Gómez JM, JA Hódar (2008) Wild boars (Sus scrofa) affect the recruitment rate and spatial distribution of holm oak (Quercus ilex). For Ecol Manage 256:1384-1389

12. Gómez-Aparicio L, Zamora R, Gómez JM, Hódar JA, Castro J, Baraza E (2004) Applying plant facilitation to forest restoration: a Meta analysis of the use of shrubs as nurse plants. Ecol Appl 14:1128-1138

13. Gonza'lez-Rodrı'guez V, Navarro-Cerrillo RM, Villar R (2011) Artificial regeneration with Quercus ilex L. and Quercus suber L. by direct seeding and planting in southern Spain. AnnFor Sci 68:637-646

14. Gratani L, Catoni R, Varone L (2011) Quercus ilex L. carbon sequestration capability related to shrub size. Environ Monit Assess 178(14):383-392

15. Harris JA, Hobbs RJ, Higgs E, Aronson J (2006) Ecological restoration and global climate change. Restor Ecol 14:170-176

16. Horak R, Župunski M, Pajević S, Borišev M, Arsenov D, Nikolić N, Orlović S (2019) Carbon assimilation in oak (Quercus spp.) populations under acute and chronic high-temperature stress. Photosynthetica 57(3):875-889

17. Jump AS, Mátyás C, Peñuelas J (2009) The altitude-for-latitude disparity in the range retractions of woody species. Trends in Ecology Evolution 24:694-701

18. Kelly AE, Goulden ML (2008) Rapid shifts in plant distribution with recent climate change. Proc Natl Acad Sci USA 105:11823-11826

19. Kremer A (1986a) Origin expression variations (juvenile-adult correlation and origin x middle interaction). Quantitative and explanatory approach. Genetic Improvement: 40-47

20. Lanly JP (2010) Factors of Deforestation and Forest Degradation, 8th World Forest Congress, Quebec City, Canada

21. Lempereur M, Martin-StPaul NK, Damesin C, Joffre R, Ourcival JM, Rocheteau A, Rambal S (2015) Growth duration is a better predictor of stem increment than carbon supply in a Mediterranean oak forest: implications for assessing forest productivity under climate change. New Phytol 207:579-590

22. Leverkus AB, Castro J, Delgado-Capel MJ, Molinas-González C, Pulgar M, Marañón-Jiménez S, Delgado-Huertas A, Querejeta JI (2015) Restoring for the present or restoring for the future: enhanced performance of two sympatric oaks (Quercus ilex and Quercus pyrenaica) above the current forest limit. Restor Ecol 23(6):936-946. https://dx.doi.org/10.1111/rec.12259

23. Limousin JM (2009) Vulnerability of green oak (Quercus ilex L.) to an increase in drought: What functional adjustments? Thesis, Montpellier SUPAGRO (International Center for Higher Studies in Agricultural Sciences): 250p

24. MacDougall AS, Duwyn A, Jones NT (2010) Consumer-based limitations drive oak recruitment failure. Ecology 91:2092-2099

25. Manrique M, Reque J (2014) Mass diversification of Pinus halepensis Mill. By directly planting acorns from Quercus ilex L. University of Valladolid. http://uvadoc.uva.es/handle/10324/6655

26. Matías L, Jump AS (2014) Asymmetric changes of growth and reproductive investment herald altitudinal and latitudinal range shifts of two woody species. Glob Change Biol 21:882-896

27. McCreary D (2009) Regenerating rangeland oaks in California, vol 21601e. University of California, Agricultural and Natural Reorigins Publication, Oakland

28. Nardini A, Salleo S, Tyree MT, Vertovec M (2000) Influence of the ectomycorhizas formed by Tuber melanosporum Vitt. on hydraulic conductance and water relations of Quercus ilex L.seedlings. Ann For Sci 57:305-312

29. NasrallahY (2014) Characterization of the morphological variability of 21 Algerian green oak origins (Quercus rotundifolia Lam.). Evaluation of their ecological adaptation in the semi-arid region of Saida. Ph.D. in Agricultural Sciences, National Higher Agricultural School (ENSA) El Harrach, $179 \mathrm{p}-2 \mathrm{~d}$ annexes

30. Nasrallah Y, Khelifi L (2010) Early diagnosis of the recovery of young plants fromeleven Algeriangreenoakorigins (QuercusrotundifoliaLam.): Consequencesfor reforestation. Mr Rev School (Earth Life) 65:359-368

31. Oubrahim H, Boulmane M, Bakker MR, Augusto L, Halim M (2015) Carbon storage in degraded cork oak (Quercus suber) forests on flat low lands in Morocco Forest. Bioscience Forestry 9(1):125-137

32. Padilla FM, Pugnaire FI (2009) Species identity and water availability determine establishment success under the canopy of Retama sphaerocarpa shrubs in a dry environment. Restor Ecol 17(6):900-907

33. Pandey A, Arunachalam K, Thadani R, Singh V (2020) Forest degradation impacts on carbon stocks, tree density and regeneration status in banj oak forests of Central Himalaya. Ecol Res 5(1):208-218. https://doi.org/10.1111/1440-1703.12078

34. Pausas JG, Keeley JE (2009) A burning story: The role of fire in the history of life. BioScience59:593-601

Page 9/14 
35. Pema'n J, Voltas J, Gil-Pelegrin E (2006) Morphological and functional variability in the root system of Quercus ilex L. Subject to confinement: consequences for afforestation. Ann For Sci 63:425-430

36. Prévosto B, Ripert C, Ostermeyer R (2013) Is clearing enough to promote the regeneration of white oak? A look back at an experimental device installed 27 years ago in the Lure State Forest (Alpes-de-Haute-Provence). Mediterranean Forest 34(1):3-12

37. Prévosto B, Reque J, Ripert C, Gavinet J, R Estève (2015) Sow Mediterranean oaks (Quer-cus ilex, Quercus pubescens): why, how and with what success? Mediterranean Forest 36(1):3-16

38. Pugnaire Fl, Armas C, Maestre FT (2009) Positive plant interactions in the lberian Southeast: Mechanisms, environmental gradients, and ecosystem function. Ann For Sci 66:511. Available online at: www.afs-journal.org

39. Quézel P, Medail F (2003) Ecology and biogeography of the forests of the Mediterranean basin. Elsevier, Paris, 573 pp

40. Rochon C, Hank A, Margolis John C, Weber C (2007) Genetic variation in growth of Guazuma crinita (Mart.) trees at an early age in the Peruvian Amazon. For Ecol Manage 234(2-3):291-298. https://dx.doi.org/10.1016/j.foreco.2007.03.025

41. Saleo S, MA LoGullo (1990) Sclerophylly and plant water relations in three Mediterranean Quercusspecies. Ann Bot 65:259-270

42. Sebei H, Albouchi A, Rapp M, El Aounid MH (2004) Biomass productivity of cork oak in a degradation sequence of the suberay at Cytise de Kroumirie (Tunisia). Ann. For Sci (61):347-361

43. Smit CH, Díaz M, Jansen P (2009) Establishment limitation of holm oak (Quercus ilex subsp. ballota (Desf.) Samp.) in a Mediterranean savanna-forest ecosystem. Ann For Sci 66(5):511p1-511p7. http://dx.doi/10.1051/forest/2009028

44. Somot S, Sevault F, Deque M, Crepon M (2008) 21st century climate change scenario for the Mediterranean using a coupled atmosphereocean regional climate model. Global Planetary Change63:112-126

45. Sotelo Montes C, Vidaurre H, Weber JC (2003) Variation in stem-growth and branch-wood traits among origins of Calycophyllum spruceanum Benth.from the Peruvian Amazon. New Forest 26:1-16

46. Tsakaldimi M, Tsitsoni T, Ganatsas P, Zagas T (2009) A comparison of root architecture and shoot morphology between naturally regenerated and container-grown seedlings of Quercus ilex. Plant Soil 324:103-113

47. Tsakaldimi M, Zagas T, Tsitsoni T, Ganatsas $P$ (2005) Root morphology, stem growth and field performance of seedlings of two Mediterranean evergreen oaks species raised in different container types. Plant Soil 278:85-93

48. Tsakaldimi MN (2001) Research on the production and quality assessment of the container-planting stock used in the afforestations. Ph.D Thesis, Aristotle University, Department of Forestry and Natural Environment, Thessaloniki. 198 pp

49. Tsoumou BR, Lumandé KJ, JP Kampé and Nzila JD (2016) Estimate of the amount of carbon sequestered by the Dimonika Model Forest (Southwest of the Republic of Congo). Scientific review Technique Forest Environment of the Congo Basin 6:39-45

50. Vennetier M, Ripert C (2010) Impact of climate change on Mediterranean flora: theory and practice. Climate change and biodiversity: 75-87

51. Vernier M, Teissier Du E, Cros (1996) Genetic variability of beech. Importance forreforestation in Picardy and Normandy. RFF - Number 1:7. https://doi.org/10.4267/2042/26731

52. Villar-Salvador P, Planelles R, Enriquez E, Penuelas-Rubira J (2004) Nursery cultivation regimes, plant functional attributes and field performance relationships in the Mediterranean oak Quercus ilex L. Forest Ecol Manag 196:257-266

53. Weber JC, Sotelo Montes C (2005) Variation and correlations among stem growth and wood traits of Calycophyllum spruceanum Benth. from the Peruvian Amazon. Silvae Genetica 54:31-41

54. Woodworth P (2013) Our once and future planet restoring the world in the climate change century. University of Chicago Press, Chicago, 529 $\mathrm{pp}$

55. Zitouni W (2010) Growth and productivity of a green oak tail at the edge of the Ain Mimoun pine forest - Ouled yagoub massif. Mem Mag. Sci. Agro. Batna: 65 pp

\section{Tables}

Table 1: Ecological characteristics and geographic coordinates of zones (provenances) related to the 21 green oak origins

NTA: North Tellian Atlas, STA: South Tellian Atlas, IP: Inner Plains, SA: Saharan Atlas.

Table 2. Adjusted regression equation for individual shrub biomass determination. DTB1: dry total biomass site1, DTB2: dry total biomass site 2, D1 and D2: plant diameter of the first and second site, respectively. 


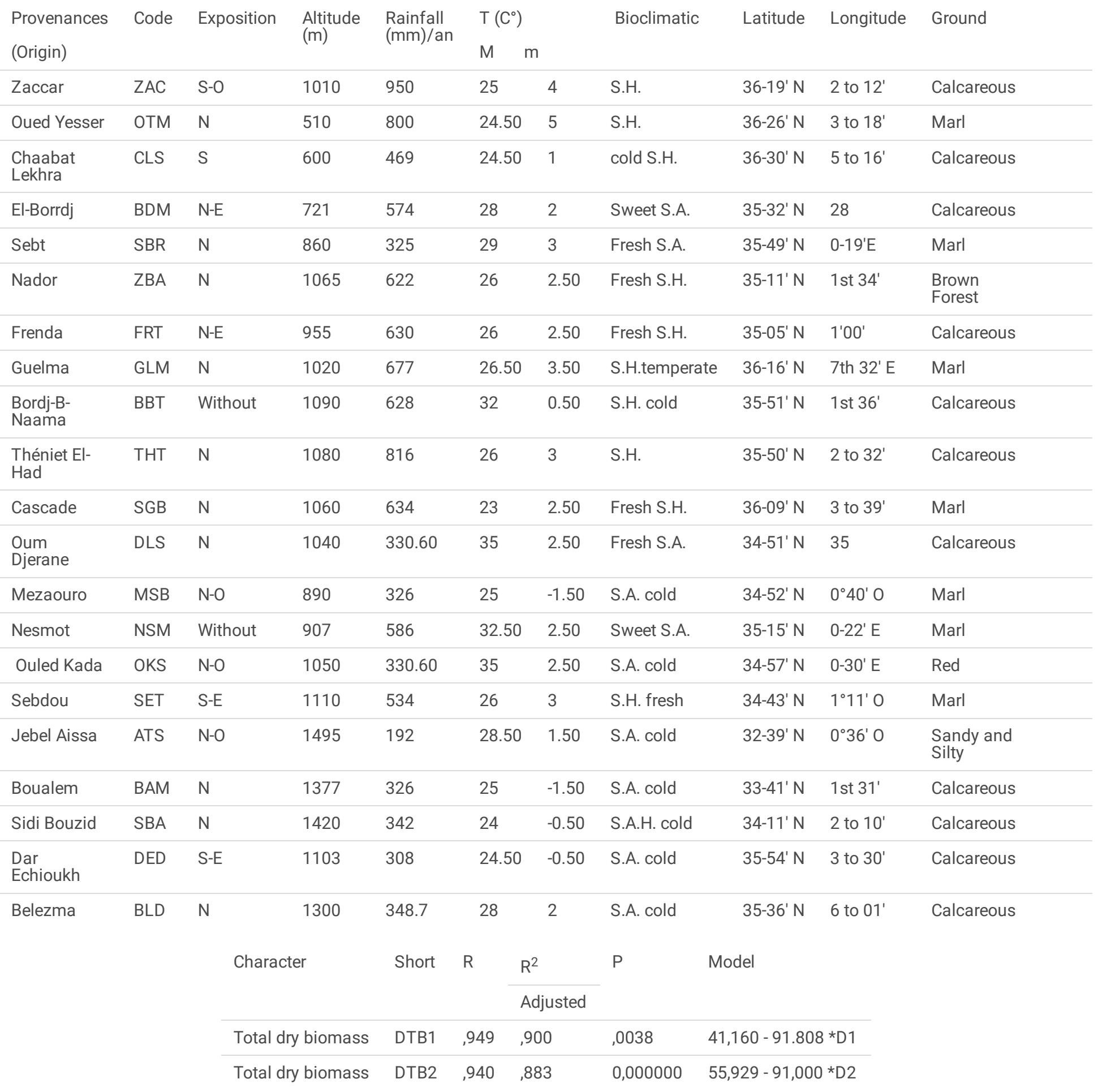

Table 3. Variance analysis of the survival rates and of the height growth of the 21 origins of green oak plants at the Sidi Benkadour and Sidi Moussa sites. The averages $(n=21)$ followed by a different letter are significantly different according to the Newman-Keuls test ( $p<0.05)$. 


\begin{tabular}{|c|c|c|c|c|c|c|c|c|c|}
\hline & \multirow[t]{2}{*}{ Prov } & \multirow{2}{*}{$\begin{array}{l}\text { \% survival } \\
\text { site } 1\end{array}$} & \multirow[t]{2}{*}{ H.G. } & $\%$ survival & H.G. & \multirow[t]{2}{*}{ Growth $(\mathrm{cm})$ site 1} & \multirow[t]{2}{*}{ H.G. } & \multirow[t]{2}{*}{ Growth (cm) site 2} & \multirow[t]{2}{*}{ H.G. } \\
\hline & & & & \multicolumn{2}{|l|}{ site 2} & & & & \\
\hline \multirow{3}{*}{ Zones } & OTM & 0.39 & $\mathrm{bc}$ & 0.2 & $a$ & 123.57 & \multicolumn{2}{|r|}{99.64} & a \\
\hline & ZAM & 0.33 & $a b$ & 0.29 & abcde & 139.3 & \multicolumn{2}{|r|}{123.49} & $a b c$ \\
\hline & CLS & 0.41 & abcd & 0.25 & $a b c$ & 124.73 & \multicolumn{2}{|r|}{114.04} & $a b c$ \\
\hline \multicolumn{10}{|l|}{ I } \\
\hline & CSG & 0.29 & $a$ & 0.31 & bcdefg & 129.24 & $\mathrm{bc}$ & 114.78 & $a b c$ \\
\hline & Avg & 0.36 & & 0.26 & & 129.21 & & \multicolumn{2}{|l|}{112.99} \\
\hline & BBT & 0.44 & bcde & 0.25 & $a b c$ & 125.92 & $a b$ & 98.36 & $a$ \\
\hline & BDM & 0.42 & bcde & 0.25 & $a b c$ & 134.82 & cdef & 122.22 & $a b c$ \\
\hline & THT & 0.45 & bcdef & 0.23 & $a b c$ & 131.65 & bcd & 126.63 & $a b c$ \\
\hline & FRT & 0.39 & $a b c$ & 0.21 & Off & 123.8 & $a b$ & 106.34 & $a b$ \\
\hline & SBR & 0.54 & ef & 0.28 & abcd & 136.98 & def & 113.36 & $a b c$ \\
\hline \multirow[t]{6}{*}{ II } & GLM & 0.4 & abcd & 0.29 & abcde & 121.27 & $a$ & 109.41 & $a b$ \\
\hline & ZBA & 0.46 & cdef & 0.35 & defg & 130.88 & bcd & 125.39 & $a b c$ \\
\hline & NSM & 0.48 & cdef & 0.26 & abcd & 131.58 & bcd & 103.66 & $a b$ \\
\hline & Avg & 0.45 & & 0.27 & & 129.61 & & \multicolumn{2}{|l|}{113.17} \\
\hline & SET & 0.39 & $a b c$ & 0.3 & bcdef & 127.63 & $a b c$ & 117.22 & $a b c$ \\
\hline & DIS & 0.43 & bcde & 0.38 & efg & 130.33 & bcd & 125.16 & $a b c$ \\
\hline \multirow[t]{5}{*}{ III } & MSB & 0.38 & $a b c$ & 0.23 & $a b c$ & 131.37 & bcde & 111.00 & $a b$ \\
\hline & OKS & 0.46 & cdef & 0.39 & $\mathrm{fg}$ & 130.4 & bcd & 108.02 & $a b$ \\
\hline & Avg & 0.42 & & 0.32 & & 129.93 & & \multicolumn{2}{|l|}{115.35} \\
\hline & ATS & 0.53 & def & 0.33 & cdefg & 13155 & bcd & 139.26 & $\mathrm{C}$ \\
\hline & BAM & 0.57 & $f$ & 0.33 & cdefg & 157.65 & $\mathrm{~g}$ & 132.73 & $\mathrm{bc}$ \\
\hline \multirow[t]{4}{*}{ IV } & SBA & 0,46 & cdef & 0,26 & abcd & 124,71 & $a b$ & 104,75 & $a b$ \\
\hline & DED & 0.5 & cdef & 0.4 & $\mathrm{~g}$ & 138.53 & ef & 126.66 & $a b c$ \\
\hline & BLD & 0.4 & $\mathrm{bc}$ & 0.26 & abcd & 128.9 & $\mathrm{bc}$ & 102.58 & $a$ \\
\hline & Avg & 0.49 & & 0.32 & & 136.26 & & \multicolumn{2}{|l|}{121.19} \\
\hline
\end{tabular}




$\begin{array}{lllllllll}\text { Overall average } & 0.46 & b & 0.31 & a & 132.10 & \text { b } & 113.80 & \text { a }\end{array}$

\section{I-North of the Tellian Atlas, II-South of the Tellian Atlas, III-Inner Plains, IV-Saharan Atlas}

H.G: homogeneous groups, Pro: provenance, Avg: average.

Table4. Analysis of the variance of dry epigeous biomass and the amount of carbon sequestered by green oak plants at the 21 origins at the Sidi Benkadour and Sidi Moussa sites. The averages $(n=21)$ followed by a different letter are significantly different according to the Newman-Keuls test $(p<0.05)$.

\begin{tabular}{|c|c|c|c|c|c|c|c|c|c|}
\hline \multirow[t]{2}{*}{ Ecological Zone } & \multirow[t]{2}{*}{ Prov } & \multirow{2}{*}{$\begin{array}{l}\text { FTB } \\
\text { site } 1\end{array}$} & \multirow[t]{2}{*}{ H.G } & \multirow{2}{*}{$\begin{array}{l}\text { FTB } \\
\text { site } 2\end{array}$} & \multirow[t]{2}{*}{ H.G } & \multirow{2}{*}{$\begin{array}{l}\text { C } \\
\text { site } 1\end{array}$} & \multirow[t]{2}{*}{ H.G } & \multirow{2}{*}{$\begin{array}{l}\text { C } \\
\text { site } 2\end{array}$} & \multirow[t]{2}{*}{ H.G } \\
\hline & & & & & & & & & \\
\hline & OTM & 380.48 & a & 350.96 & a & 145 & a & 126.52 & $\mathrm{a}$ \\
\hline & Raise & 474.22 & i & 430.12 & $a b$ & 180.74 & i & 154.99 & $a b$ \\
\hline \multirow[t]{5}{*}{1} & CLS & 377.34 & a & 360.97 & a & 143.8 & a & 130.12 & a \\
\hline & CSG & 429.81 & defg & 409.47 & $a b$ & 163.81 & defg & 147.57 & $a b$ \\
\hline & Avg & 415.46 & & 387.88 & & 158.34 & & 139.8 & \\
\hline & BBT & 399.32 & $a b c$ & 518.24 & $b$ & 152.18 & $a b c$ & 186.69 & $b$ \\
\hline & BDM & 375.33 & $\mathrm{a}$ & 365.78 & a & 143.03 & a & 131.85 & $a$ \\
\hline \multirow[t]{8}{*}{ II } & THT & 445.18 & fgh & 415.74 & $a b$ & 169.67 & fgh & 149.82 & $a b$ \\
\hline & FRT & 379.53 & a & 362.23 & a & 144.63 & a & 130.57 & a \\
\hline & GLM & 393.4 & $a b$ & 368.42 & $a$ & 149.93 & $a b$ & 132.8 & a \\
\hline & ZBA & 432.71 & defg & 387.61 & $\mathrm{a}$ & 164.91 & defg & 157.28 & $a b$ \\
\hline & NSM & 450.02 & gh & 426.67 & Off & 171.52 & gh & 139.36 & a \\
\hline & Avg & 414.61 & & 419.14 & & 158.01 & & 147.84 & \\
\hline & SET & 416.56 & bcde & 389.08 & a & 158.76 & bcde & 140.23 & $a$ \\
\hline & DIS & 429.56 & defg & 420.52 & $a b$ & 163.71 & defg & 151.54 & $a b$ \\
\hline \multirow[t]{6}{*}{ III } & MSB & 394 & $a b$ & 386.66 & $a$ & 150.15 & $a b$ & 139.36 & a \\
\hline & OKS & 424.36 & cdefg & 395.68 & Off & 161.73 & cdefg & 142.6 & $a b$ \\
\hline & Avg & 416.12 & & 397.98 & & 158.59 & & 143.43 & \\
\hline & ATS & 461.79 & hi & 423.18 & $a b$ & 176 & hi & 152.5 & $a b$ \\
\hline & BAM & 400.19 & $a b c$ & 373.27 & $\mathrm{a}$ & 152.51 & $a b c$ & 134.54 & a \\
\hline & SBA & 406.63 & bcd & 387.61 & a & 154.97 & bcd & 139,7 & a \\
\hline \multirow[t]{3}{*}{ IV } & DED & 438.46 & efgh & 450.65 & $a b$ & 167.11 & efgh & 162,38 & $a b$ \\
\hline & BLD & 419.28 & bcdef & 381.04 & a & 159.79 & bcdef & 137.34 & a \\
\hline & Avg & 425.27 & & 403.15 & & 162.08 & & 145.29 & \\
\hline Overall average & & 417.87 & b & 402.04 & $\mathbf{a}$ & 159.26 & b & 144.09 & $\mathbf{a}$ \\
\hline
\end{tabular}

I-North of the Tellian Atlas, II-South of the Tellian Atlas, III-Inner Plains, IV-Saharan Atlas

H.G: homogeneous groups, Pro: provenance, C: carbon.

Figures 


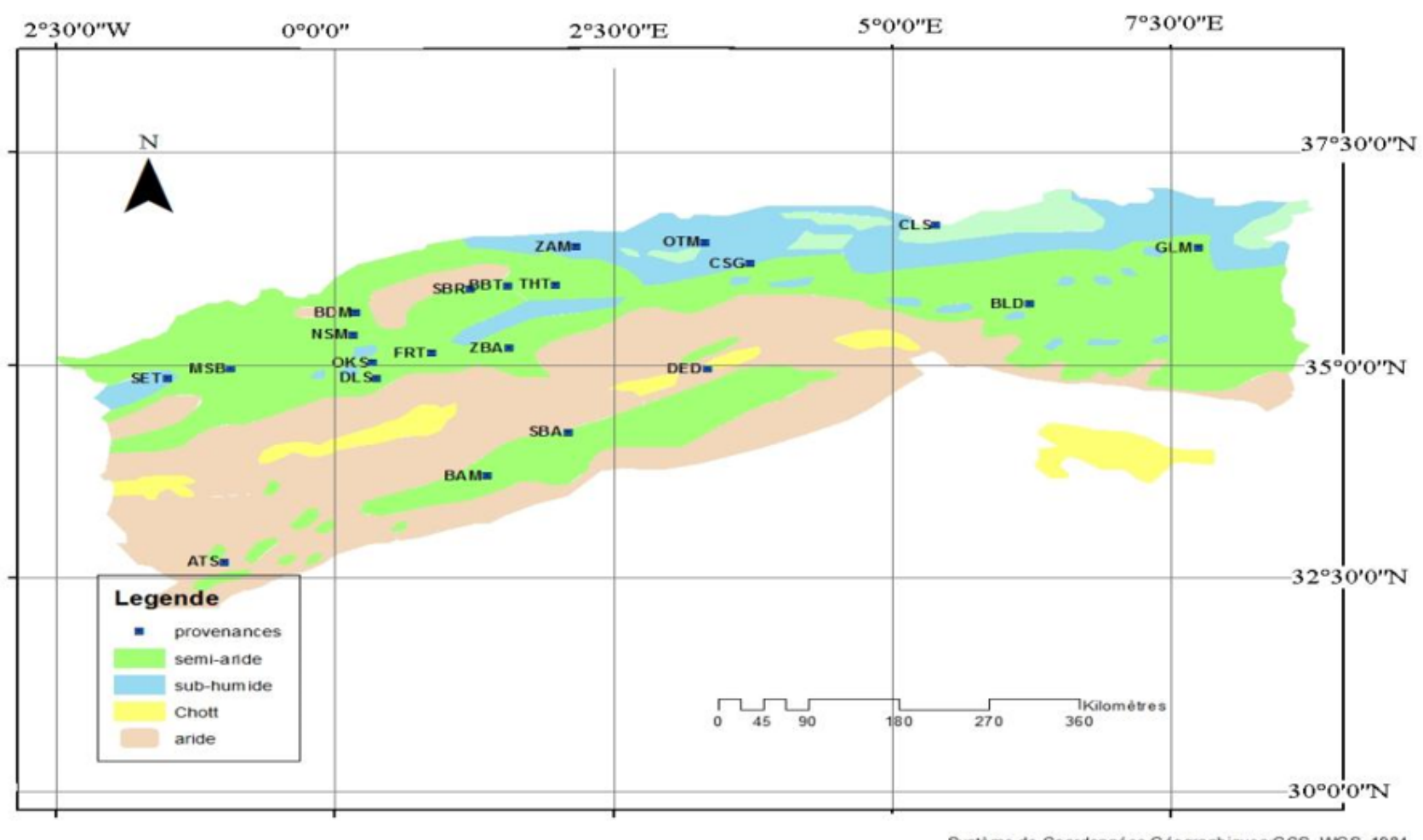

Figure 1

Location of sources on the map of bioclimatic floors in Algeria. 